\title{
Seroprevalence of HBV HCV HIV and SYPHILIS Infections among Blood Donors in South East Rajasthan- An Eleven Year Retrospective Study
}

\author{
Authors

\section{Dr Vijay Rajak ${ }^{1}$, Dr Abha Patni ${ }^{2}$, Dr Sandhya Bordia ${ }^{3}$, Dr Sanjay Prakash Dr Pooja kanwat ${ }^{5}$}

${ }^{1}$ MBBS MD, Assistant Professor, Department of Pathology, RNT Medical College, Udaipur - 313001

${ }^{2}$ MBBS MD, Professor, Department of Pathology, RNT Medical College, Udaipur - 313001

${ }^{3}$ MBBS, MD, Professor, Department of Pathology, RNT Medical College, Udaipur - 313001

${ }^{4}$ MBBS, MD, Associate Professor, Dept of Transfusion Medicine, RNT Medical College, Udaipur - 313001

${ }^{5}$ MBBS MD, Senior Resident Department of Pathology, RNT Medical college, Udaipur

\begin{abstract}
Transfusion of blood and blood products has proven to be an important aid in saving patient's life thus strengthening patient care but at the same time it could transmit infections to the recipients. We conducted a retrospective study to evaluate the prevalence of hepatitis B virus (HBV), hepatitis $C$ virus (HCV), human immunodeficiency virus (HIV) and syphilis among blood donors in a tertiary care hospital of SOUTH-EAST RAJASTHAN, an eleven year experience,2001-2011. Blood donors who were selected for the study were either replacement donors or voluntary donors. Seroprevalence of antibodies against HCV and HIV as well as HBsAg antigen was studied by Enzyme linked immunosorbent assay (ELISA) and Rapid plasma reagin was done for syphilis. Out of total 146885 blood donations $29.33 \%$ were voluntary donors and $70.67 \%$ were replacement donors. 3810 (2.59\%) donors had serological evidence of infection with at least one pathogen, either of HIV, HBV, HCV or Syphilis. These included 490(0.33\%) with HIV, 2703 (1.84\%) with HBV, 153 (0.1\%) with HCV and 464 (0.32\%) with Syphilis. Blood transfusion is becoming a leading risk factor for spread of these above mentioned infections thus showing need and importance of screening of these infections in blood donations
\end{abstract}

Key Words: Blood donors; HIV; HBV; HCV; Syphilis; Transfusion transmissible infections (TTI)

\section{INTRODUCTION}

Transfusion of blood and blood products is a lifesaving phenomenon that forms a vital part of various medical and surgical therapy and health care system and there is no genuine substitution for blood. Timely transfusion of blood has saved millions of lives, Moreover, blood transfusion improves the quality of life of multi transfused patients like thalassemia, hemophilia etc. Blood transfusion reduces morbidity and mortality in clinical conditions which cannot be prevented or managed otherwise .Even though blood saves lives, unsafe transfusion practices can put many people at risk of transfusion-transmissible 
infections (TTIs). Morbidity and mortality resulting from the transfusion of infected blood have far-reaching consequences, not only for the recipients themselves, but also for their families, their communities and the wider society .The most prior objective of Blood transfusion services(BTS) is to ensure safety(elimination of TTIs), adequacy, accessibility and efficiency of blood supply at all levels.

Strict donor selection criteria, sensitive screening tests, restriction of donation by professional donors, reduction of unnecessary transfusion and effective inactivation procedures can ensure the elimination, or at least reduction in TTIs. As per Drug and Cosmetic Act, 1945, it is mandatory to screen blood for presence of HIV I \& II, HBsAg, $\mathrm{HCV}$, and syphilis infections before transfusion. The Indian subcontinent is classified as an intermediate Hepatitis B Virus (HBV) endemic (HBsAg carriage 2-7\%) zone and has the second largest global pool of chronic HBV infections with 43 million HBV positive[1]. India has a second highest pool of HIV patients in the world with 5.7 (reduced to 2.5) million Human Immunodeficiency Virus (HIV) seropositive [2][3][1]. In India there are 15 million Hepatitis C Virus (HCV) positive persons ${ }^{[1]}$. With the advancement of nucleic acid tests (NAT-PCR),for
TTI screening may reduce the risk of TTI's. Country has shown decline in the risk of TTI. Our retrospective study was aimed to evaluate the prevalence of transfusion transmissible infections among healthy donors over a period of time so as to heighten the awareness of the infectious complications of blood transfusion. It also gives us the idea of disease burden of the society and the basic epidemiology of these diseases in the community.

\section{MATERIALS AND METHODS}

Our retrospective study was carried out at blood bank, Maharana Bhopal govt. hospital Udaipur, rajasthan (a tertiary care hospital) during January 2001 to December 2011. Only selected donors were bleed who fullfilled blood donor selection criteria as per drug and cosmetic act. This screening procedure was very helpful to exclude the professional donors. The serum sample was then subjected to serological test. The screening for HIV antibody, $\mathrm{HBsAg}$ antigen and $\mathrm{HCV}$ antibody was done by 3rd generation ELISA. Test for Syphilis was done by RPR test. Seropositive blood bags were discarded. The data were properly recorded on tabulated, analyzed and compared with the similar studies by other author

TABLE 1. Total blood collection and sex distribution of donors in the present study

\begin{tabular}{|c|c|c|c|c|c|}
\hline year & $\begin{array}{c}\text { Total } \\
\text { donors }\end{array}$ & $\begin{array}{c}\text { Voluntary } \\
\text { donors }\end{array}$ & $\begin{array}{l}\text { Replacement } \\
\text { donors }\end{array}$ & males & Females \\
\hline 2001 & 9434 & 1126 & 8308 & 9038 & 396 \\
\hline 2002 & 9456 & 1370 & 8086 & 8994 & 462 \\
\hline 2003 & 10128 & 2083 & 8045 & 9557 & 571 \\
\hline 2004 & 10853 & 2228 & 8625 & 10319 & 534 \\
\hline 2005 & 11856 & 3075 & 8781 & 11218 & 638 \\
\hline 2006 & 16771 & 4198 & 12573 & 15626 & 1145 \\
\hline 2007 & 17589 & 4801 & 12788 & 16504 & 1085 \\
\hline 2008 & 15788 & 4036 & 11752 & 14734 & 1054 \\
\hline 2009 & 15127 & 7779 & 7348 & 14184 & 943 \\
\hline 2010 & 14059 & 5304 & 8755 & 13022 & 1037 \\
\hline 2011 & 15824 & 7086 & 8738 & 14690 & 1134 \\
\hline TOTAL & 146885 & $43086(29.33)$ & 103799(70.67) & $137886(93.87)$ & $8999(6.13)$ \\
\hline
\end{tabular}

Note: Numbers in parenthesis indicates percentage 
TABLE 2. Seroprevalence of HIV, HBsAg, HCV and Syphilis in blood donors

\begin{tabular}{|c|c|c|c|c|c|c|}
\hline year & $\begin{array}{c}\text { Total } \\
\text { donors }\end{array}$ & $\begin{array}{c}\text { Total } \\
\text { infective }\end{array}$ & HBsAg & HIV & HCV & VDRL \\
\hline 2001 & 9434 & 449 & $248(2.63)$ & 37(0.39) & $6(0.06)$ & 158(1.67) \\
\hline 2002 & 9456 & 296 & 207(2.19) & $34(0.36)$ & $6(0.06)$ & $49(0.52)$ \\
\hline 2003 & 10128 & 327 & 261(2.57) & $30(0.29)$ & $13(0.13)$ & $23(0.23)$ \\
\hline 2004 & 10853 & 310 & 201(1.85) & $54(0.49)$ & 33(0.30) & $22(0.20)$ \\
\hline 2005 & 11856 & 317 & 218(1.84) & $52(0.44)$ & $12(0.10)$ & $35(0.29)$ \\
\hline 2006 & 16771 & 421 & $326(1.94)$ & $58(0.34)$ & $25(0.15)$ & $12(0.07)$ \\
\hline 2007 & 17589 & 457 & $326(1.85)$ & $65(0.37)$ & 31(0.17) & $35(0.19)$ \\
\hline 2008 & 15788 & 392 & 274(1.73) & $53(0.33)$ & $7(0.04)$ & $58(0.37)$ \\
\hline 2009 & 15127 & 324 & 237(1.57) & $42(0.28)$ & $8(0.05)$ & $37(0.24)$ \\
\hline 2010 & 14059 & 271 & $210(1.49)$ & 37(0.26) & $9(0.06)$ & $15(0.11)$ \\
\hline 2011 & 15824 & 246 & 195(1.23) & $28(0.18)$ & $3(0.02)$ & $20(0.12)$ \\
\hline TOTAL & 146885 & $3810(2.59)$ & $2703(1.84)$ & $490(0.33)$ & $153(0.1)$ & $464(0.32)$ \\
\hline
\end{tabular}

Note: Numbers in parenthesis indicates percentage

TABLE 3. Prevalence of TTI'S among replacement (RD) and voluntary(VD) donors

\begin{tabular}{|c|c|c|c|c|c|c|c|c|}
\hline \multirow{3}{*}{$\begin{array}{l}\text { YEAR } \\
2001\end{array}$} & \multicolumn{2}{|c|}{ HBsAg } & \multicolumn{2}{|c|}{ HIV } & \multicolumn{2}{|c|}{$\mathrm{HCV}$} & \multicolumn{2}{|c|}{ VDRL } \\
\hline & RD & VD & RD & VD & RD & VD & RD & VD \\
\hline & $221(2.34)$ & $27(0.28)$ & $35(0.37)$ & $2(0.02)$ & $6(0.06)$ & $\mathbf{0}$ & 157(1.66) & $1(0.01)$ \\
\hline 2002 & 182(1.92) & $25(0.26)$ & $28(0.29)$ & $6(0.06)$ & $6(0.06)$ & 0 & $49(0.52)$ & 0 \\
\hline 2003 & $204(2.01)$ & $57(0.56)$ & $28(0.27)$ & $2(0.02)$ & 11(0.11) & $2(0.02)$ & $22(0.22)$ & $1(0.01)$ \\
\hline 2004 & 159(1.46) & $42(0.38)$ & $50(0.46)$ & 4(0.03) & 21(0.19) & 12(0.11) & $22(0.20)$ & 0 \\
\hline 2005 & 178(1.50) & $40(0.34)$ & 47(0.39) & $5(0.04)$ & $8(0.06)$ & $4(0.03)$ & $35(0.29)$ & $\mathbf{0}$ \\
\hline 2006 & 264(1.57) & $62(0.37)$ & $58(0.34)$ & 0 & $24(0.14)$ & $1(0.006)$ & $12(0.07)$ & $\mathbf{0}$ \\
\hline 2007 & 246(1.39) & $80(0.45)$ & $56(0.32)$ & $9(0.05)$ & $24(0.13)$ & $7(0.04)$ & $35(0.19)$ & 0 \\
\hline 2008 & 218(1.38) & $56(0.35)$ & 49(0.32) & $4(0.02)$ & $6(0.04)$ & $1(0.006)$ & $54(0.34)$ & $4(0.02)$ \\
\hline 2009 & $108(0.71)$ & $129(0.85)$ & $26(0.17)$ & $16(0.11)$ & $5(0.03)$ & $3(0.02)$ & $28(0.18)$ & $9(0.06)$ \\
\hline 2010 & $130(0.92)$ & $80(0.57)$ & $35(0.25)$ & $2(0.01)$ & $7(0.05)$ & $2(0.01)$ & 13(0.09) & $2(0.01)$ \\
\hline 2011 & $116(0.73)$ & $79(0.49)$ & $24(0.15)$ & $3(0.02)$ & $2(0.01)$ & $1(0.006)$ & $18(0.11)$ & $2(0.01)$ \\
\hline TOTAL & $2026(1.38)$ & $677(0.46)$ & $436(0.29)$ & $53(0.04)$ & $120(0.08)$ & $33(0.02)$ & $445(0.30)$ & 19(0.01) \\
\hline
\end{tabular}

Note: Numbers in parenthesis indicates percentage

\section{OBSERVATIONS}

During our study period, Out of 146885 blood donors 137886 were males and 8999 were females (M:F ratio 93.87:6.13).

Voluntary donation outnumbered the replacement donation as shown in Table 1. The overall prevalence of $\mathrm{HBsAg}, \mathrm{HIV}, \mathrm{HCV}$ and syphilis were $1.84,0.33,0.1,0.32$ respectively. The highest prevalence was of HBsAg followed by HIV followed by syphilis and the least prevalent was HCV (Table 2). Prevalence of TTI's were more in replacement donors than voluntary donors. Prevalence of infections ( HBsAg, HIV, $\mathrm{HCV}$, syphilis) among replacement donors were
$1.38,0.29,0.08,0.30$ while in that of voluntary donors were $0.46,0.04,0.02,0.01$ (Table 3).

Fig 1-4 shows the changing trends in seroprevalence of HBsAg, HIV, HCV and syphilis during our study period. A very slight declining trend is seen in overall seroprevelance of HBsAg during the study period with the highest value of 2.63 in 2001 and the lowest of 1.23 in 2011. If seen individually, there is a remarkable decline in the prevalence of $\mathrm{HBsAg}$ in replacement donors with the highest value of 2.34 in 2001 and lowest value of 0.73 in 2011 without much change in the prevalence in voluntary donors. The overall prevalence of syphilis has decreased within years 


\section{JMSCR VoI||3||Issue||10||Page 8068-8073||October}

but this declining trend is more visible in replacement donors as compared to voluntary donors. The highest prevalence of syphilis was seen in the year $2001(1.67 \%)$. In the year 2001 and 2002 prevalence of $\mathrm{HCV}$ was low and constant (0.06), there was a increasing trend from
2003 to 2007 with the peak value in 2004 (0.30) but it decreased thereafter. Both replacement and voluntary donors showed same decrement in the prevelance of HCV. The overall Seropositivity of $\mathrm{HIV}$ as well as that in replacement and voluntary donors has decreased.
HBsAg PREVALENCE

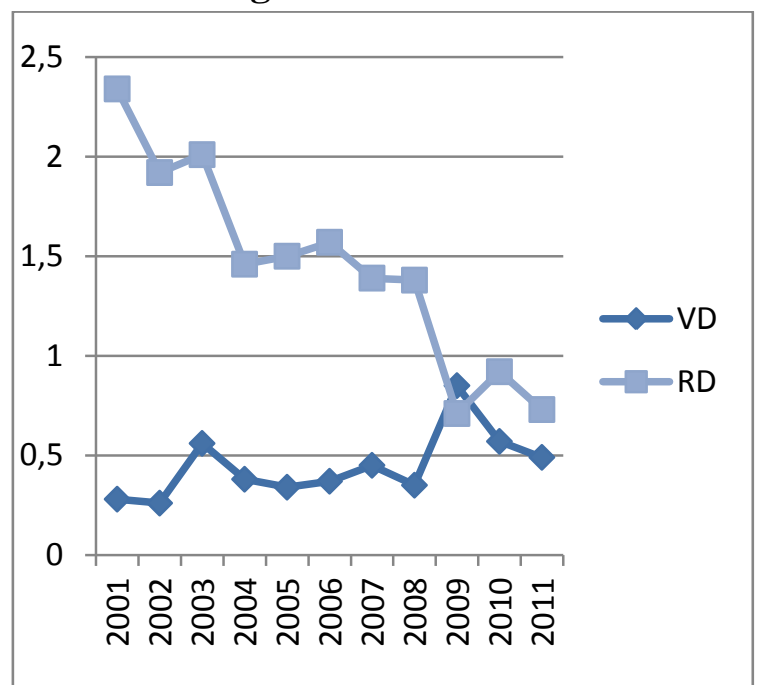

HCV PREVALENCE

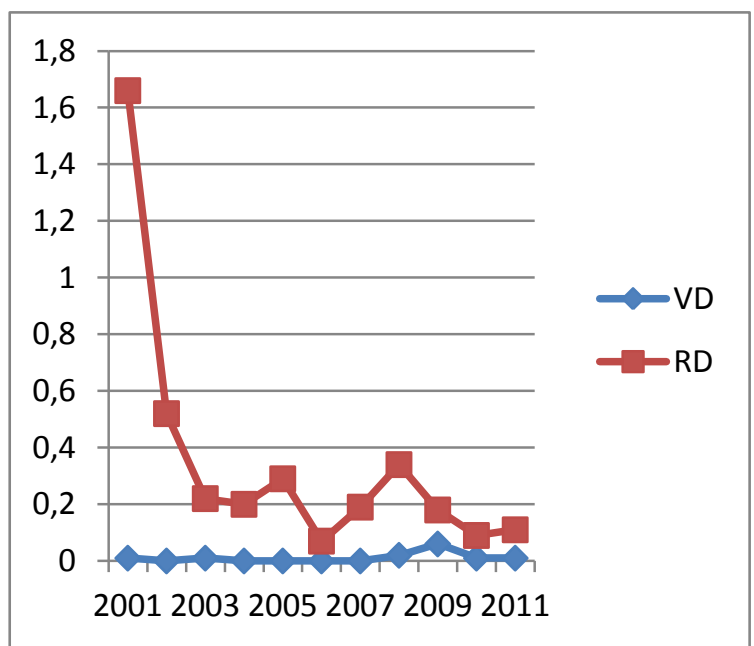

HIV PREVALENCE

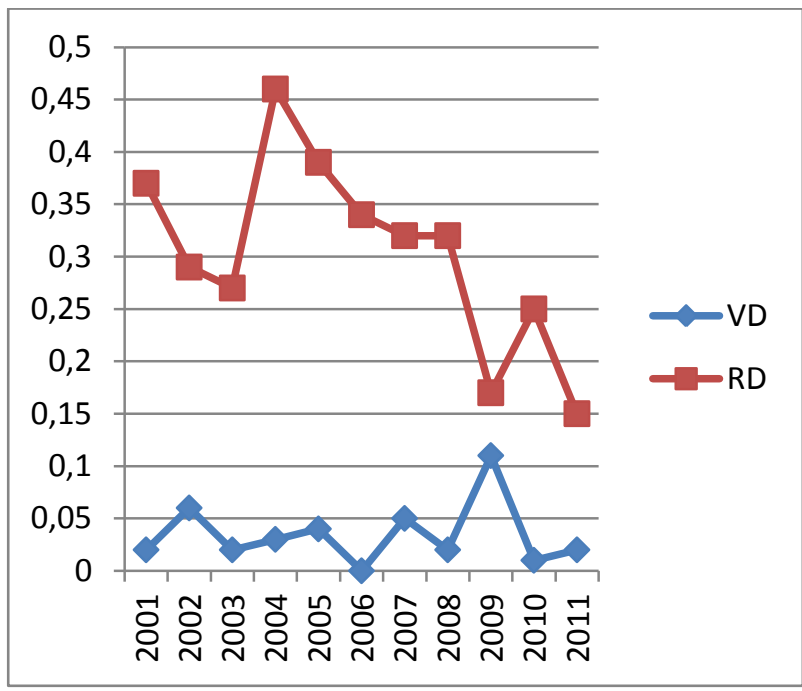

SYPHILIS PREVALENCE

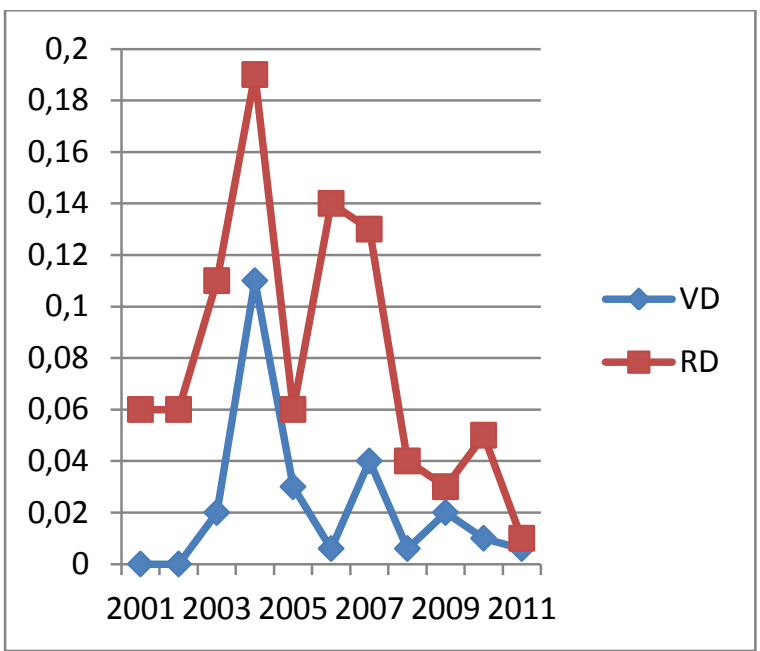

\section{DISCUSSION}

Transfusion Transmissible Infections (TTI's) continue to be a major threat to safe transfusion practice .Despite our vigilance towards transfusion transmitted infections and vigorous screening of donors and donated blood units, there are potential chances of transmission of these infections through blood. With every unit of blood there is $1 \%$ chance of transfusion associated problem including TTI's ${ }^{[4]}$. Therefore it is necessary to ensure the safety of blood and blood products before transfusion. Due to lack of awareness and presence of social and cultural taboos in society voluntary donors were less $(29.33 \%)$ as compared to replacement donors (70.62\%). This is in contrast to the study done by Bhattacharya et al ${ }^{[2]}$ and Pallavi et al ${ }^{[5]}$, who found a predominance of Voluntary Donors . In the present study TTI were more prevalent in 
Replacement Donors . Similar observations are reported by most of the studies done in india ${ }^{[4][6][7][8][3][9][10]}$. Females made a smaller section of the study as they were found to be anaemic and did not fulfill the required donor fitness criteria. The detailed analysis and comparison of TTIs with the studies by different authors within India is described in table 4 . In the present study, the overall prevalence of TTI's was found to be $2.55 \%$ which was almost similar to those found by Gupta et al ${ }^{[6]}(2.68 \%)$, Chandra et al ${ }^{[7]}(2.54 \%)$ and Bhawani et al ${ }^{[3]}(2.72 \%)$. In the present study we found that HBV is the commonest TTI, which is again similar to the most of the other studies Chandra et al ${ }^{[7]}$, Nilima Sawke et al ${ }^{[8]}$, Bhawani et al ${ }^{[3]}$, Jasani et al ${ }^{[9]}$ and Dayal et al ${ }^{[10]}$ and Bhattacharya $P$ et al ${ }^{[2]}$. However, Gupta et al ${ }^{[6]}$ reported $\mathrm{HCV}$ as the most common TTI .The major route of $\mathrm{HBV}$ transmission is parenteral and it is the most infective agent among blood-borne viruses .Individuals with chronic HBV infection have a high risk of developing liver cirrhosis and hepatocellular carcinoma. HCV was found to be the second most common TTI found among blood donors by most of the workers, but in the present study HCV is the least common TTI among the blood donors with seroprevalence rate of $0.1 \%$. A similar low prevalence of $\mathrm{HCV}$ of $0.23 \%$ was reported by Pallavi et al ${ }^{[5]}$ from mysore. Majority of the HCV infected persons progress to chronic infection and chances of cirrhosis and hepatocellular carcinoma are more as compared to chronic HBV infection. Blood is one of the main sources of transmission of HepatitisB and C; hence, donor selection criteria and proper TTI screening is of paramount importance. The prevalence of HIV in various parts of india is different with higher rate in western and southern parts ${ }^{[11]}$. In the present study, HIV was the second most common TTI with prevalence of $0.33 \%$, a similar prevalence of $0.39 \%$ of HIV was observed by Bhawani et al ${ }^{[3]}$ in Andra Pradesh.

For Syphilis, the seroprevalence was found to be $0.31 \%$ which is low like most of the other reported studies (Gupta $\mathrm{N}$ et al ${ }^{[6]}$, Bhattacharya $\mathrm{P}$ et al ${ }^{[2]}$, Jasani et al ${ }^{[9]}$. In our study, overall prevalence of TTI's has shown a declining trend during the study period of 11 years. This is mainly because of advancement in screening techniques and newer generation kits and also because of the increasing knowledge of the people regarding the transmission of the various diseases and increasing public awareness through mass media and various social organization

TABLE 4. Comparison of prevalence of TTIs with various studies in India.

\begin{tabular}{|c|c|c|c|c|c|c|}
\hline Author and year & place & $\begin{array}{l}\text { Total } \\
\text { TTI's }\end{array}$ & HBsAg & HIV & HCV & Syphilis \\
\hline Gupta et al & Ludhiana & $2.68 \%$ & $0.66 \%$ & $0.08 \%$ & $1.09 \%$ & $0.85 \%$ \\
\hline Chandra et al (2009) & Lucknow, U.P & $2.54 \%$ & $1.96 \%$ & $0.23 \%$ & $0.34 \%$ & $0.01 \%$ \\
\hline Nilima Sawke et al (2010) & Bhanpur, M.P. & $4.21 \%$ & $2.90 \%$ & $0.51 \%$ & $0.57 \%$ & $0.23 \%$ \\
\hline Bhawani et al (2010) & Vikarabad, AP & $2.72 \%$ & $1.41 \%$ & $0.39 \%$ & $0.84 \%$ & $0.08 \%$ \\
\hline Jasani et al (2012) & Piparia Gujarat & $3.35 \%$ & $1.35 \%$ & $0.25 \%$ & $0.85 \%$ & $0.90 \%$ \\
\hline Dayal et al (2011) & Etawah, UP & $3.16 \%$ & $2.63 \%$ & $0.19 \%$ & $0.34 \%$ & Not done \\
\hline Bhattacharya et al (2007) & Kolkata, West Bengal & $2.80 \%$ & $1.46 \%$ & $0.28 \%$ & $0.31 \%$ & $0.72 \%$ \\
\hline Present study & Udaipur, Rajasthan & $2.55 \%$ & $1.81 \%$ & $0.33 \%$ & $0.1 \%$ & $0.31 \%$ \\
\hline
\end{tabular}




\section{REFRENCES}

1. Giri PA, Deshpande JD, Phalke DB, Karle LB et al- Seroprevalence of transfusion transmissible infections among voluntary blood donors at a tertiary care teaching hospital in rural area of India. J Fam Med Primary Care 2012;1:48-51.

2. Bhattacharya P,Chakraborty S,Basu SK et al- Significant increase in HBV,HCV,HIV and Syphilis infections among blood donors in West Bengal,Eastern india 20042005.Exploratory screening reveals high frequency of occult HBV infection. World J Gastroenterol 2007;13 : 3730- 3733.

3. Yedlapati Bhawani, P Raghava Rao, V Sudhakar et al- Seroprevalence of transfusion transmissible infections among blood donors in a tertiary care hospital of Andhra Pradesh from. 2004-2009.Biology and Medicine 2010; 2 (4): 45-48.

4. Arora D, Arora B, Khetarpal A et al Seroprevalence of $\mathrm{HIV}, \mathrm{HBV}, \mathrm{HCV}$ and Syphilis in blood donors in Southern Haryana. Ind $\mathbf{J}$ Pathol Microbiol 2010;53:308-309.

5. Pallavi P,CK Ganesh,K Jayashree,GV Manjunath et al-Seroprevalence and Trends in transfusion transmitted infections among blood donors in a university hospital blood bank: A 5 year study(2004-2008).Ind J Hematol Blood Transfuse (2011) 27(1):1-6.

6. Gupta N, Kumar V, Kaur A.et alSeroprevalence of HIV, HBV, HCV and syphilis in voluntary blood donors. Ind $\mathrm{J}$ Med Sci. 2004; 58: 255-257.

7. Chandra T, Kumar A, Gupta A et alPrevalence of transfusion transmitted infections in blood donors: an Indian experience. Transfusion.2009; 49(10): 2214-20.

8. Sawke N, Sawke G K, Chawla S et al Seroprevalence Of Common TransfusionTransmitted infections among Blood Donors at Bhanpur, B h o p a $1, \mathrm{M}$. P ,from 2006-2008.Peoples J Of sci. Research 2010;3(1) 5-7.

9. Jasani J, Patel V, Bhuva K, Vachhani A, Patel H, Falleiro J J et al- Sero-prevalence of transfusion transmissible infections among blood donors in a tertiary care hospital. Int J Biol Med Res. 2012; 3(1): 1423-1425.

10. Dayal S, Omar B J, Sipai H H, Agarwal S $\mathrm{K}$, Chandra S, Chaturvedi $\mathrm{V}$ et alPrevalence of transfusion transmitted Viral Diseases among blood donors in a rural setup of North India from 2006-2011.Int J Sci Tech and Management. 2011; 2(3): $97-$ 99.

11. Singh B ,Verma M,Kotru M,Verma $\mathrm{K}$, Batra $\mathrm{M} \mathrm{t}$ al- Prevalence of HIV and VDRL Seropositivity in blood donors of Delhi. Ind J Med Res2005;122:234-236. 